Chapter 24

\title{
Facial Augmentation with Implants
}

\author{
Farzin Sarkarat, Behnam Bohluli and \\ Roozbeh Kahali \\ Additional information is available at the end of the chapter \\ http://dx.doi.org/10.5772/59188
}

\section{Introduction}

The public's demand for facial beauty has increased over time. Different cosmetic procedures have been introduced to meet this demand. The essentials of facial cosmetic surgery are: 1Volume replacement and 2- Facial augmentation. Better aesthetic results have been achieved by using less invasive surgical techniques including lifting procedures, injectable fillers, autologous fat transfer, and facial implants.

The malar eminence and chin are the most common facial sites augmented via implants. Autologous tissues have been the gold standard for facial augmentation for years; but today alloplastic materials are more commonly used.

Drawbacks of autogenous grafting include: donor site morbidity, limited availability, limited moldability, and unpredictable resorption [1].An ideal alloplastic implant must be made out of a material that has low bioactivity or toxicity. It must also be stable and biocompatible [2]. An understanding of these qualities is needed to prevent complications or to treat them should they occur.

\section{The aging process}

One of the primary advancements in cosmetic facial surgery has been the realization of volume loss in aging and volume replacement via cosmetic surgery [3-6]. The abundance of midfacial volume is one of the main reasons that makes a person look young, which means having the right amount of fat in the right areas of the face. The loss or shift of this fat is a main contributor to facial aging [7]. Loss of volume and volume shift occur in all regions of the face and neck and are the reasons for aged appearance [5,6].The youthful midface has voluminous and 
superiorly positioned malar fat pads. The malar fat pad is a triangular structure with its base against the nasolabial fold and its apex over the malar region. Due to actinic skin changes as well as gravity, fat atrophy, and deep connective tissue laxity, the malar fat pads lose volume and descend lower into the face with age. The sum of these aging changes frequently yields a hollow midface.

\section{Treatment}

There are a wide variety of procedures for achieving volume replacement and facial augmentation including lifting procedures [7, 8], injectable fillers [9-11], autologous fat transfer [12, 13], and facial implants [14, 15]. Facial implants are an optimum for most patients. The main advantage is that they are a permanent option when compared with fillers; and they are available in many anatomical shapes and sizes. They are easily placed, the recovery is minimal, and they have a low complication rate.

Autogenous bone and cartilage have been used to repair traumatic, congenital, and surgical defects of the face. The increased morbidity of the donor site, limited supply, resorption, and migration contributed to decrease in their use. Gold, silver, paraffin, and ivory fell out of favor because of their tissue incompatibility and lack of malleability. Polymeric silicone, polyamide mesh, expanded polytetrafluoroethylene, and high-density polyethylene, replaced the previous materials because of their increased malleability and biocompatibility [16].

The midface is the area in which facial implants are more commonly used. Implants in the nasojugal crease are used to correct tear trough deformity. Nasal implants are not widely used, but can be used to correct defects caused by rhinoplasty. Malar and submalar implants (Figure 1) are the most commonly used implants in the midface [17].

The lower face is another area where facial implants are frequently used. Chin implants (Figure 2) are one of the most common facial implants performed by cosmetic surgeons [18]. Volume restoration, in addition to the re-suspension and removal of excess tissue, remains the current goal of aesthetic surgery. Facial implants play a major role in volume restoration.

\section{Implant types}

Facial implants are categorized according to their site (malar, submalar, paranasal, chin, etc.). They can also be prefabricated, anatomical or custom-made. Facial implants are available in many shapes and sizes. The submalar implant is best described as an implant that restores the volume the patient has lost with age. This is in contrast to malar augmentation, which generally changes a patient's appearance while augmenting volume. Volume is lost in the malar region but is significantly less than the volume lost in the submalar region. Smaller implants generally restore a former appearance, whereas larger implants change the patient's appearance. The submalar zone is the area of maximum midface atrophy in most patients. Most female patients 
are treated with a small submalar implant. The medium implant is most frequently used in the male patient. If the patient is looking for replacement of atrophic losses that occur with aging, the smaller implant is preferable. A larger implant is reserved for the patient who desires to not only replace volume that has been lost but also augment an appearance that was previously unsatisfactory to the patient. Microgenia is effectively addressed with chin augmentation [19, 20]. The placement of an extended alloplastic anatomic chin implant is a simple, safe, and easily performed procedure. The patient's appearance is enhanced by restoring the chin and cervico-mental region [21,22]. Most patients with a mild to moderately deficient chin are well treated with an alloplastic implant [19]. In patients with severe microgenia, a chin implant combined with soft tissue filling and tension restoration is most effective.

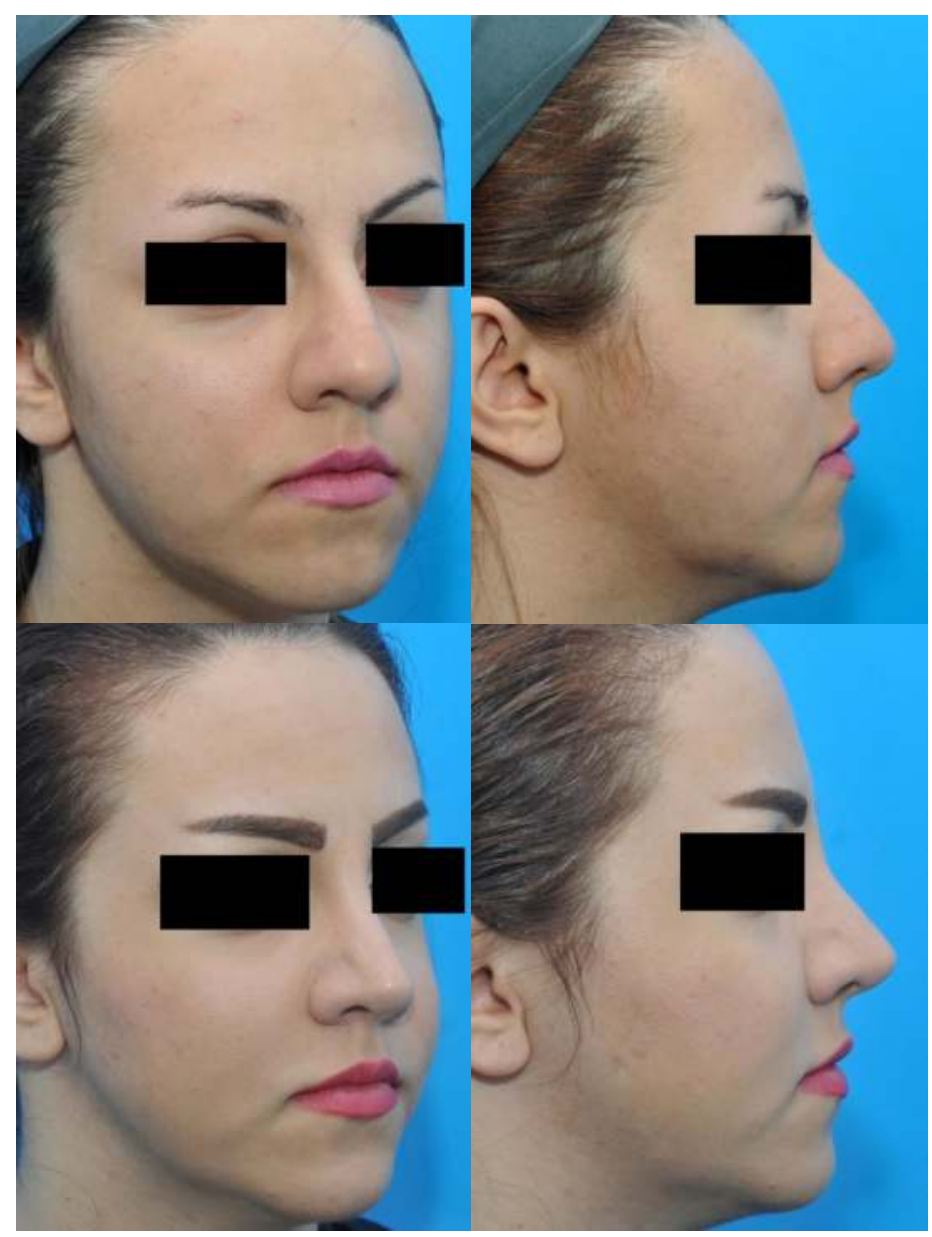

Figure 1. Malar augmentation with facial implant. Above: Before. Below: After. 


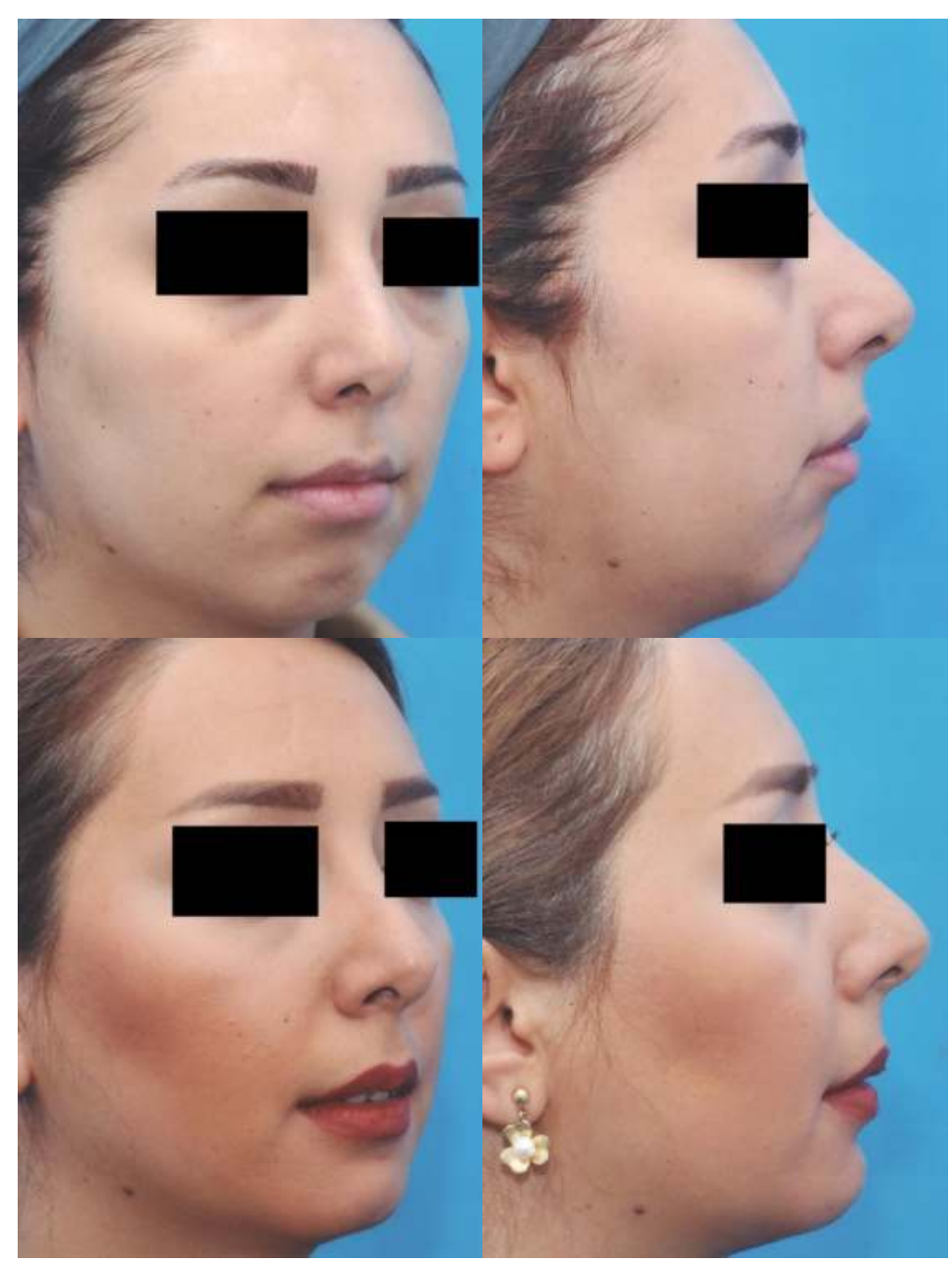

Figure 2. Chin augmentation with facial implant, Above: Before, Below: After.

Facial implants are made of various materials. It is crucial that the surgeon be familiar with these materials and their advantages and disadvantages.

\subsection{Metal implants}

Cobalt chromium alloys, stainless steel, gold, and titanium have been used as facial implants. The corrosive characteristics of metals placed in the body limited their use. Stainless steel was used in the plating of skeletal fractures of the face. Titanium has largely replaced stainless steel and cobalt-chromium alloys as the metal of choice because of its strength, low tissue reactivity, reduced artifact on $\mathrm{CT}$, safety during MRI studies and its corrosive resistance over time [23]. 
Its use is generally limited to dental implants and facial skeletal plating for maxillofacial trauma [1, 24, and 25].

\subsection{Silicone implants}

Silicone implants have been used for years. Polydimethylsiloxane is nonporous implant with smooth contours. Its pliable nature and resistance to high temperatures used in sterilization make it the most versatile facial implant. It also can be easily carved and shaped. Polydimethylsiloxane becomes encapsulated in a mild chronic inflammatory process. Because no links are formed between the polydimethylsiloxane and its fibrous tissue envelope, they are more prone to displacement, persistent seromas and a tendency toward extrusion [26-29].

\subsection{Polyester fiber}

Polyester fiber is comprised of nonabsorbable strands of polyethylene terephthalate which is a porous material, allowing tissue ingrowth and subsequent implant stability. The excellent tensile strength, durability, biocompatibility, and flexibility of polyester fiber have led to its use in facial implants. Infection rates are lowered with antibiotic impregnation [30, 31]. Its disadvantages are the surgical time required to prepare the mesh with folding and suturing and inflammatory reactions most commonly seen after facial trauma [32].

\subsection{Polyamide mesh}

Polyamide mesh is an organopolymer related to nylon. It has the advantage of flexibility, ease of molding and allowing tissue ingrowth into the implant which is related to the implant stability. Polyamide mesh creates an intense foreign body response and chronic inflammation. Hydrolytic degradation has been noted to occur after implantation, leading to loss of volume [33].

\subsection{High-density polyethylene}

High-density polyethylene (HDPE) which is more commonly known as "Medpor" (Prex Surgical, Inc., College Park, Georgia), is a stable, porous and extremely inert implant with minimal foreign body reactions which does not degrade over time. It is malleable when heated but otherwise has a lack of pliability. Although the large average pore size encourages fibrous tissue ingrowth, leading to firm attachment and high stability [34, 35], but fibrous ingrowth does not guarantee stability of HDPE implants against bone and may require additional fixation.

\subsection{Polymethylmethacrylate}

Polymethylmethacrylate (PMMA) has high strength and rigidity for bony reconstruction of the face. It has been used to repair orbital, malar, and cranial defects [36-38]. PMMA is available as a powder consisting of polymer and catalyst and a liquid form of the monomer. When mixed, an exothermic reaction occurs. The heat generated by the reaction has led to untoward events in orthopedic surgery, although such complications have not been reported in craniofacial 
reconstruction. PMMA is well tolerated without significant inflammatory foreign body reactions. Being able to create customized implants unique to each patient's needs is one of its main advantages.

\subsection{Expanded polytetrafluoroethylene}

ePTFE known as "Gore-Tex" (W.L.Gore and Associates, Flagstaff, AZ), is a fibrillated polymer of polytetrafluoroethylene, with pores between the fibrils averaging 22 microns in diameter which allows limited soft tissue ingrowth while creating only a mild chronic inflammatory response, providing early stabilization and permitting removal when necessary [39]. ePTFE is spongy in consistency, inert, and does not change shape or resorb with time. It also has been found to be non-carcinogenic and is rarely allergenic [28, 40]. Because ePTFE is hydrophobic, it does not absorb antibiotic solutions [41].

\subsection{Hydroxyapatite}

Calcium hydroxyapatite is mixed in a fashion similar to methylmethacrylate to form a cement that can be contoured to each individual patient's needs. Because it forms the synthetic, inorganic constituent of bone, it can induce osseointegration. Mixing does not result in an exothermic reaction. It is now used more commonly as an injectable implant.

\section{Implant selection}

The surgeon must be able to make a decision regarding the selection of an implant based on chemical composition, physical structure, and planned site for application. Characteristics of an ideal implant include biocompatibility, chemical inertness, lack of elicitation of foreign body or hypersensitivity reaction, non-carcinogenicity, and ease of shaping and carving [42].

Common implant materials include expanded PTFE, methyl methacrylate, porous polyethylene, and silicone rubber. Porous polyethylene and silicone rubber implants are the most commonly used. Silicone rubber implants can be easily trimmed, being flexible, conform well to underlying anatomy and become well encapsulated. They can be easily be removed or replaced if necessary.

The structure of porous polyethylene implants allows better tissue integration, but this can also be extremely problematic when attempting to remove or replace an implant. Significant tissue injury, defects or implant fragmentation can occur with removal.

Most patients, as they age, lose volume in the submalar region. The submalar area includes the hollow area of the infraorbital, anterolateral maxillary region, and canine fossa regions. Most of these patients have a hollow submalar region. They usually have adequate and welldefined zygomatico-malar esthetics and adequately projected cheekbones. These patients are best treated with only submalar augmentation, as their problem is loss of submalar volume. 
The second type of common facial esthetic deficiency found is in patients who have adequate submalar and anterior maxillary projection but deficient cheekbones and hypoplasia of the zygomatico-malar regions. These patients are best treated with a malar implant.

The third type of common midfacial aging change is seen in a patient who has submalar deficiency in addition to need of more zygomatico-malar augmentation. These patients need both submalar and malar augmentation. These patients are well treated with the combined submalar shell implant. This implant is designed to augment the submalar region as well as a portion of the zygomatico-malar region.

Careful examination and thorough analysis aid in coming to a decision about what size of implant to use to achieve the desired effect [43]. Clinical photography serves as a powerful tool. A similar approach is applied to the chin and prejowl complex. This approach helps determine what type of implant to use.

Fewer surface imperfections allow greater resilience against degradation by mechanical forces [44]. This advantage must be balanced with the increased possibility of migration as compared with porous implants. The implant should not create a severe immune response, one that may harm the host or damage the implant. Synthetic implants stimulate inflammatory response with acute and chronic phases [45]. Significant immunogenicity can result in degradation or rejection of the implant. Bacteria are capable of implant invasion when pore size decreases. Implants with pore sizes between 1 and 50 microns may be more susceptible to infection than materials with larger pores, because they do not permit tissue granulation and delivery of host inflammatory cells to mount an adequate immune response.

\section{Implant placement}

\subsection{Malar and submalar augmentation}

The placement of midfacial implants is a simple surgical procedure for experienced maxillofacial surgeons. The implants are always placed in the subperiosteal plane. With the exception of the infraorbital neurovascular bundle, there is little vulnerable anatomy in the midface region, when dissecting in the subperiosteal plane. The implants can also be placed concomitantly with other esthetic or orthognathic procedures.

With the patient in the sitting position, the atrophic submalar area is marked and the zygomatic arch is outlined. The patient is prepared and draped. Several approaches to the malar and submalar region exist including subciliary, transconjunctival, and intraoral. The intraoral approach if preferred. The procedure is begun by injecting about $5 \mathrm{~mL}$ of $2 \%$ lidocaine with 1:100,000 epinephrine in the subperiosteal plane along the anterior maxilla, malar region, and the anterior zygomatic arch region. An incision is made just below the maxillary vestibule, approximately $1 \mathrm{~cm}$ above the canine tooth (Figure 3). The mucosa and soft tissues are incised in the canine fossa region and through the periosteum. Subperiosteal dissection is performed (Figure 4). 


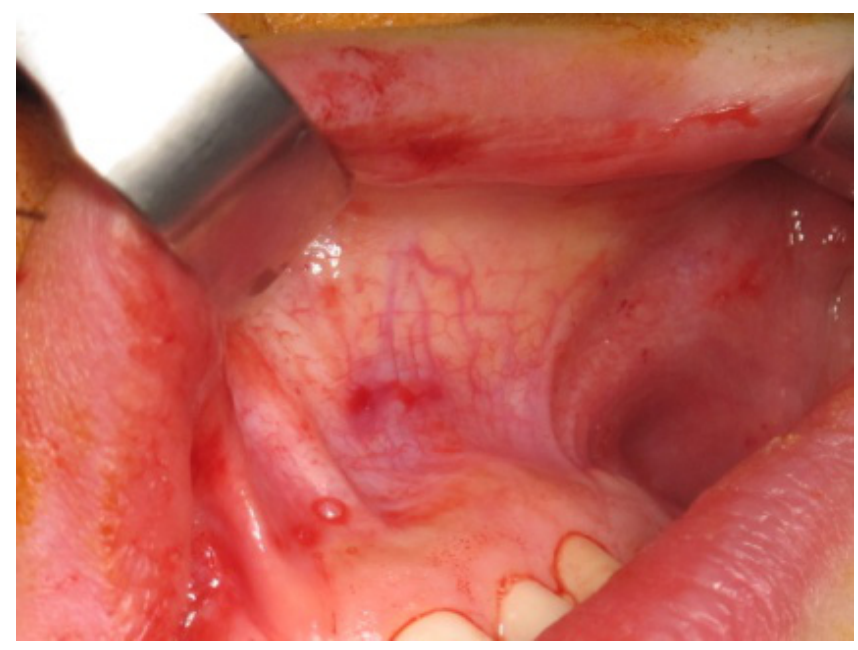

Figure 3. Intraoral approach for malar implant placement

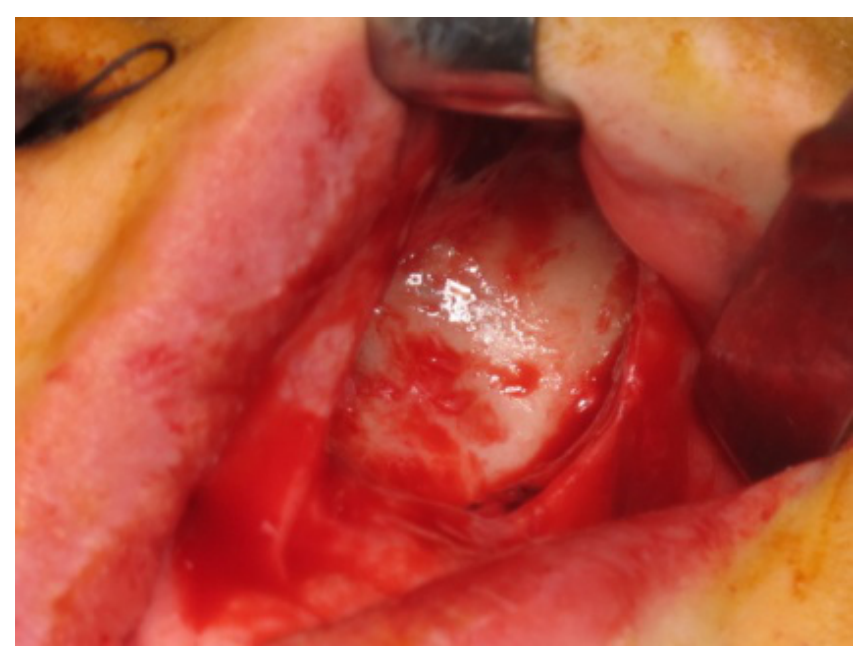

Figure 4. Subperiosteal dissection for malar implant placement

The borders of this dissection pocket are the lateral portion of the inferior orbital rim, superiorly, the zygomatic arch superolaterally and the masseteric fascia laterally. The buccal fat pad must be avoided. The extent of the dissection is dictated by the shape and size of the implant. The combined submalar and shell implants require more dissection over the malar and zygomatic regions. The dissected pocket should be just slightly larger than the actual implant size. As the subperiosteal dissection is begun in the anterior maxillary region, it is important 
to protect the infraorbital neurovascular bundle. After the anterior maxilla is dissected, the periosteal elevator is angled and the remainder of the dissection is primarily in an oblique vector over the malar region and extends over the anterior portion of the zygomatic arch. After the implant pocket is dissected, the area is checked for hemostasis (Figure 5). The pocket is then irrigated with antibiotic solution $(300 \mathrm{mg}$ of clindamycin and or gentamicin mixed with $30 \mathrm{~mL}$ of sterile water) and the implant is placed. The implants are also soaked in antibiotic solution. This is especially important for porous implants (Figure 6).

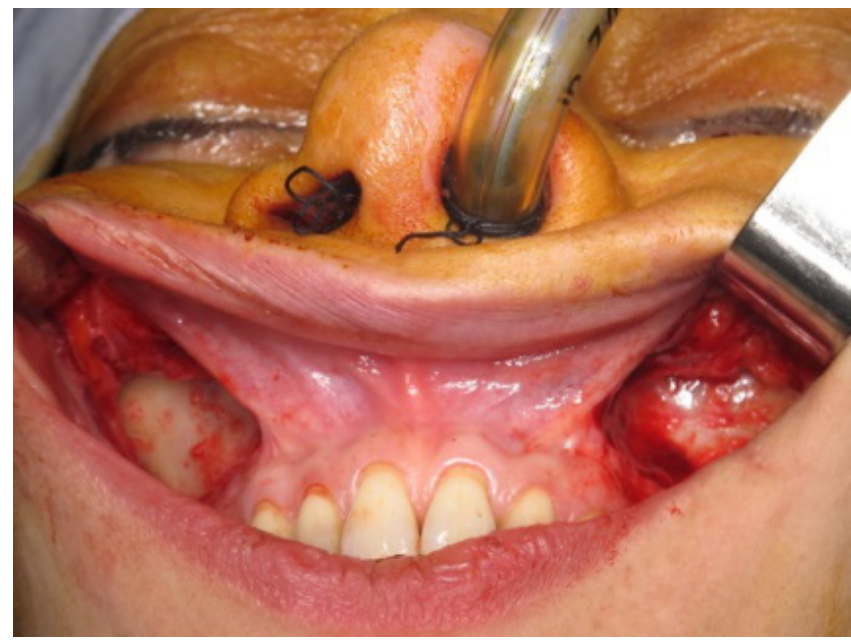

Figure 5. The subperiosteal pocket is checked for hemostasis

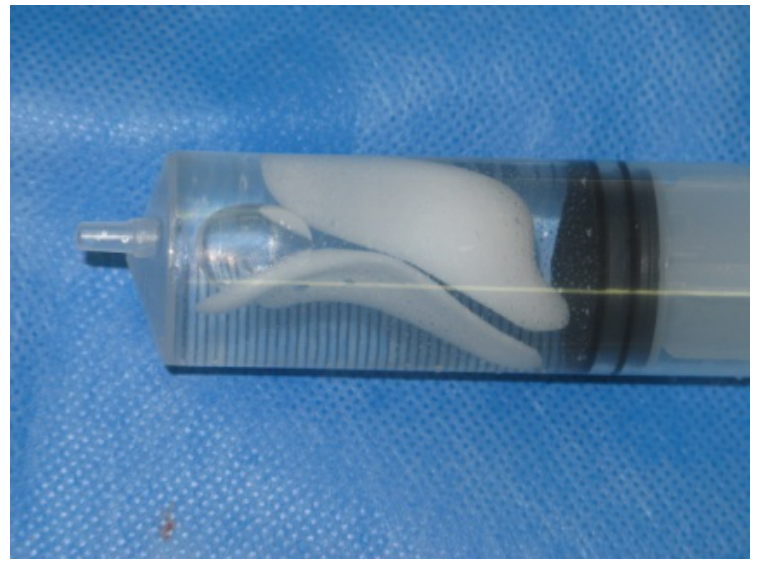

Figure 6. The implants are also soaked in Gentamicin solution 
A well-conforming implant in a tight pocket does not generally need fixation. If the pocket is considerably larger than the implant and there is increased mobility of the implant, a single fixation screw can be placed. The fixation screw is best placed in the thicker bone of the buttress area (Figure 7). Finally, the incision is closed with interrupted 4-0 absorbable suture (Figure 8).

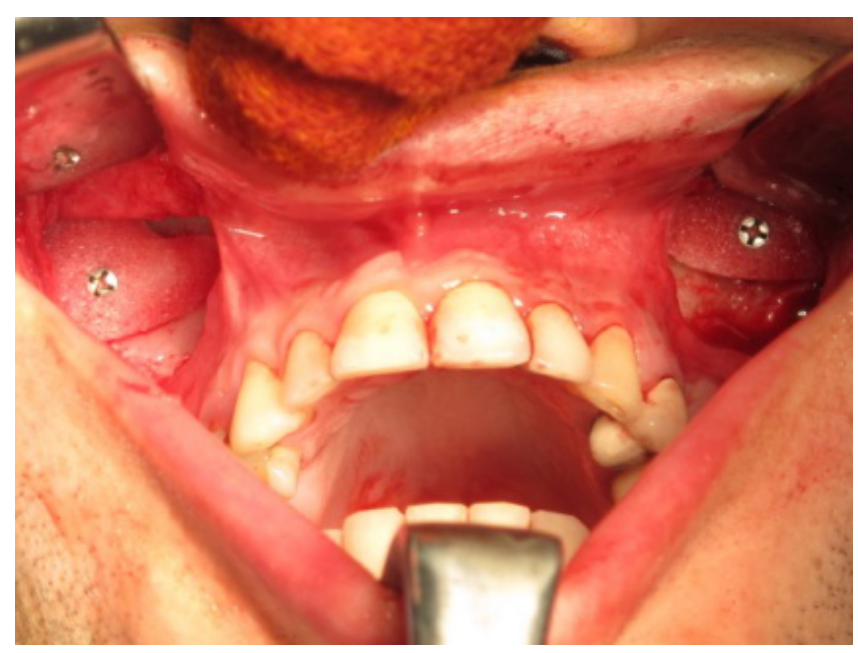

Figure 7. Implant fixation

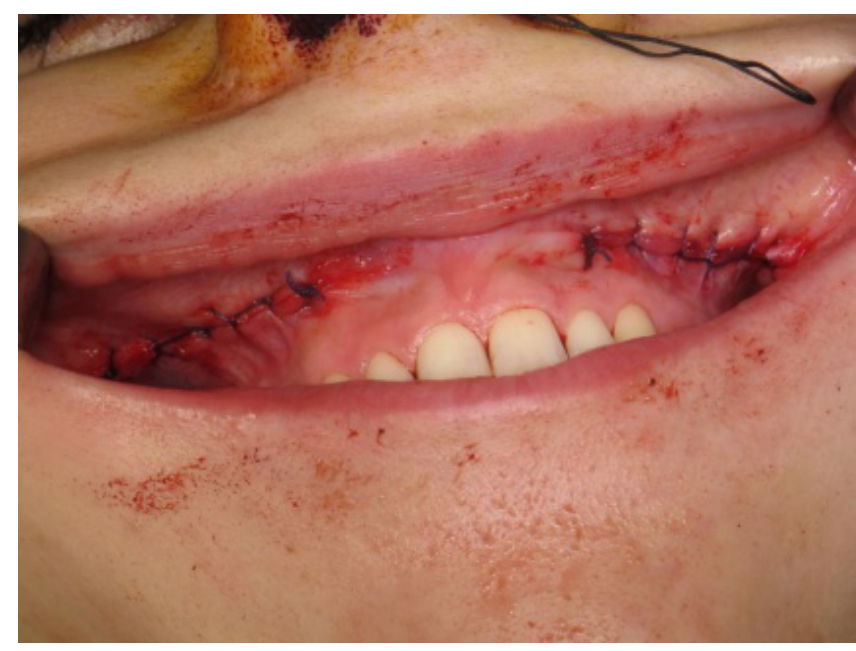

Figure 8. Incision closureChin augmentation 
There are two main approaches to chin augmentation; one with an intraoral incision, and one with an incision in the submental crease. The main advantage of the intraoral incision is the avoidance of an external scar. The submental incision is preferred because the external scar is well camouflaged in the submental crease and there is no need to divide the mentalis muscle.

A 2-cm incision is made in the submental crease centered about the midline. Sharp and blunt dissection is used to reach the periosteum of the lower edge of the mandible in the midline. A sharp incision is made through the periosteum laterally. A subperiosteal dissection is performed to create a pocket for the implant. Dissection laterally should be performed as close to the mandibular border as possible to avoid injuring the mental nerve. After the implant is inserted a stabilizing stitch or screws may be used. The incision is then closed in two layers.

When using an intra-oral approach, a 2 to $3-\mathrm{cm}$ incision is made in the mandibular labial sulcus about 10 to 15-mm away from mucogingival junction (Figure 9). Then the mentalis muscle and periosteum are transected and a subperiosteal dissection is performed (Figure 10). Care must be taken not to injure the mental nerve.

The implant is inserted over the chin bone and screws are used for fixation (Figures 11 and 12). Then the mentalis muscle portions are aligned and sutured together. The mucosa is closed with absorbable sutures.

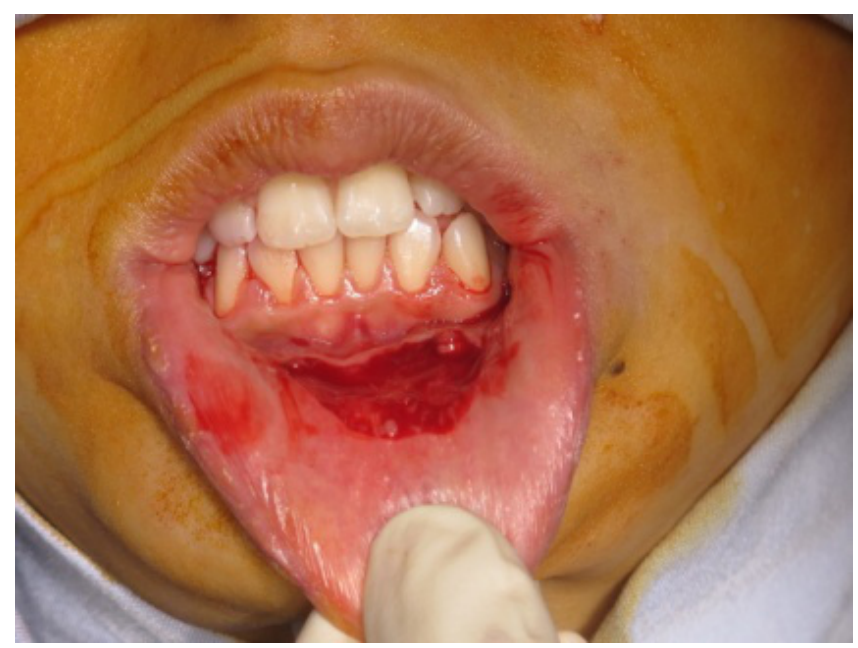

Figure 9. Intra-oral approach for chin implant placement 


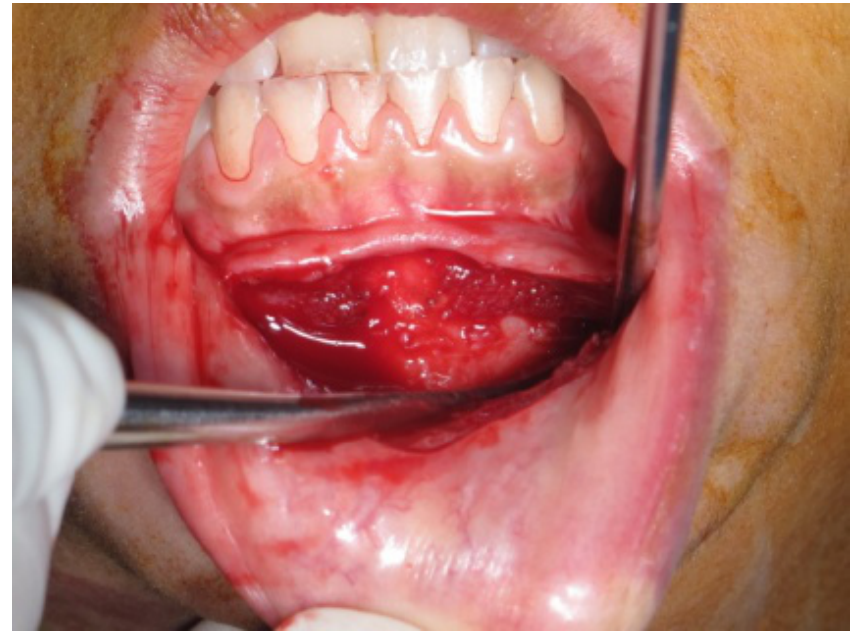

Figure 10. Subperiosteal dissection for chin implant placement

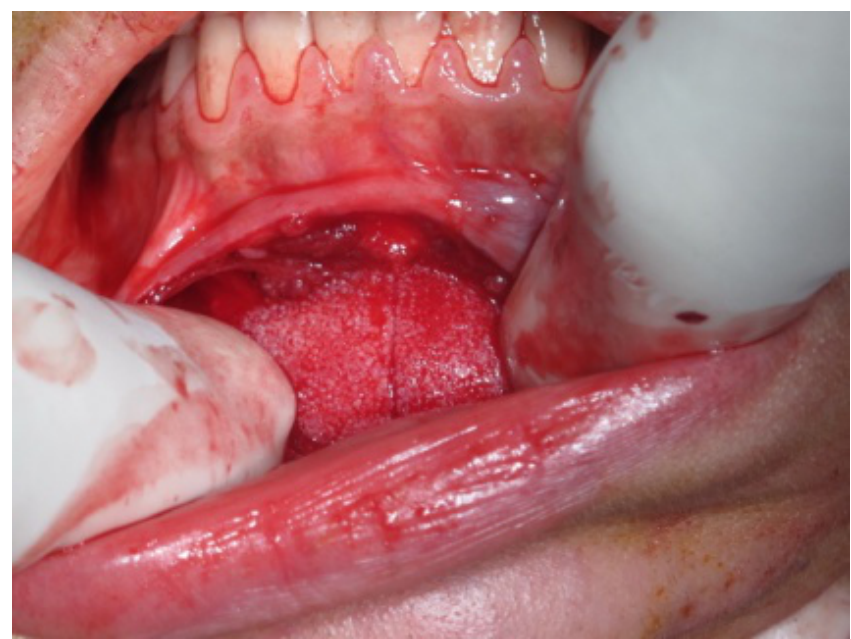

Figure 11. Implant placement 


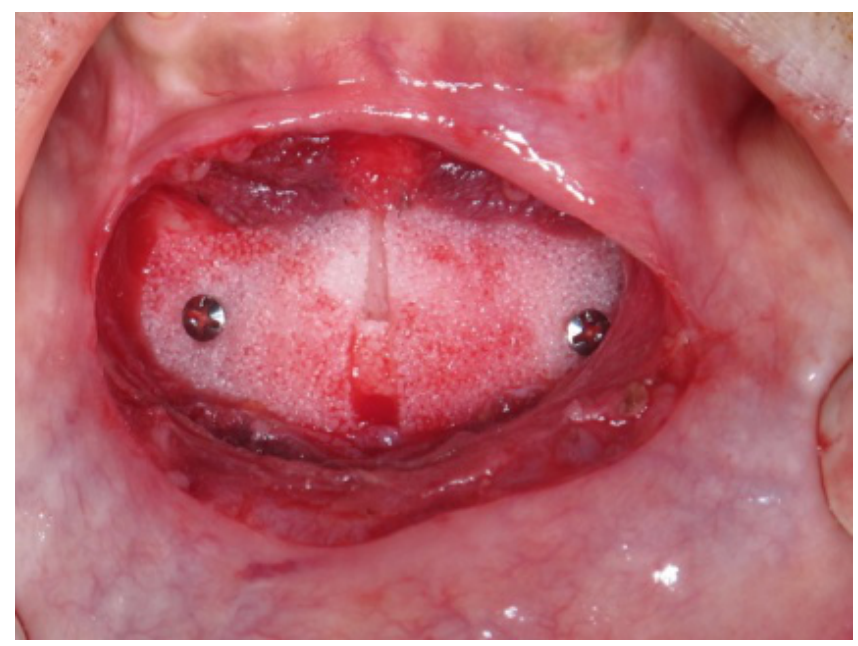

Figure 12. Implant fixation

\section{Postoperative sequelae}

The patient must be warned that during the first 1 to 2 weeks he or she will experience abnormal animation when smiling and talking. The tissue dissection violates the orbicularis oris and lip elevator muscles, which heal uneventfully with the return of normal animation. Significant edema is not uncommon, especially with larger implants and in the early postoperative period. Cold packs and steroids are routinely used. Severe swelling may indicate hematoma formation and, if necessary it must be drained. This can usually be done by opening the incision and suctioning the blood or clot from under or around the implant without compromising the result. Minor hematomas will usually heal uneventfully without treatment. Occasionally, subconjunctival or periorbital ecchymosis is seen but remains a rare occurrence and heals uneventfully.

\section{Post operative care}

No dressings are required and the postoperative care includes analgesics, antibiotics, and steroids if desired. The patient is instructed to avoid significant talking and animation for the first 48 hours and is asked to follow a liquid or soft diet for the same period. Ice packs are used for the first 24 hours. 


\section{Complications}

\subsection{Improper selection or placement}

Improper placement of the implant is the most common complication followed by improper implant selection. The implant should be slightly smaller than the desired increase in fullness. Selecting too large an implant will lead to excessive soft tissue tension, which could lead to ischemia, necrosis, or extrusion. Placement of malar implants too laterally can cause the eyes to look too close together. Placement of the implants too medially and inferiorly will give a chipmunk look or appearance.

\subsection{Neuropraxia}

Neuropraxia can occur from impingement of the nerve by a large implant, migration or improper placement of the implant, a traction injury, a thermal injury, or a direct traumatic injury from dissection. Most patients regain sensation and function within three weeks. Dissection for Malar implants involves elevating tissue around the infraorbital nerve. Weakness of the zygomaticus, orbicularis oculi, or the frontalis muscles can be induced by disturbance of the temporofrontal branch of the facial nerve while dissecting posteriorly over the middle third of the zygomatic arch. Straying from the subperiosteal plane predisposes to dissection into the parotid and facial nerve branches and facial musculature. During dissection of the chin, it is important to avoid the mental nerve, which is approximately underneath the area of the premolars intraorally. The marginal mandibular branch of the facial nerve, which supplies muscles of the lower lip and chin, is above the periosteum over the inferior border of the mandible. A severe traction injury or perforation of the periosteum can injure the marginal mandibular branch of the facial nerve.

\subsection{Edema and ecchymosis}

The majority of postoperative edema and ecchymosis resolves in two weeks, but edema can persist for 6 months and even up to a year [46]. Implant fixation is important because excessive continuing movement can cause tissue injury, chronic inflammation, and suboptimal soft tissue acceptance with prolonged edema. This could also be due to a nonspecific immune reaction to the implant material.

\subsection{Hematoma and seroma}

Abnormal fluid collection can be the result of inadequate hemostasis, over-dissection, traumatic handling of the tissues, dead space around or underneath the implant or elevated blood pressure. Hematomas and seromas encourage the growth of bacterial contamination potentiating cellulitis and infection. They can result in excessive fibrosis producing soft tissue defects. Smaller hematomas $(<5 \mathrm{cc})$ resolve without treatment in 10-14 days. Large hematomas need to be recognized and evacuated with the implant removed as necessary. Seromas usually present around 2 weeks after surgery. Presence of liquefied hematomas or seromas 2 to 4 weeks postoperatively may be drained percutaneously [47]. 


\subsection{Infection}

Implants can be contaminated by hematogenous, contiguous spread, or direct inoculation. Foreign bodies have been shown to reduce the number of bacteria required to produce an infection by 104 to 106 power [48]. Chemical composition, surface roughness, surface configuration, and hydrophobicity influence the potential for implant contamination. Hydrophilic materials are more resistant to adhesion than hydrophobic materials. Scalfani and colleagues found that PTFE with an average pore size of 22 microns became infected at lower inoculum counts and sooner than polyethylene with a pore size of 150 microns [48]. Most infections in the early postoperative time period are more likely to occur with porous implants because of increased surface area, irregularity, and surface energy, which facilitates bacterial adherence. Infections that occur years after surgery are most probably caused by hematogenous spread or direct violation of the implant capsule with bacterial seeding like an injection. Late malar implant infections have been associated with dental injections as reported by Cohen and Kawamoto [49].

S. aureus is the main pathogen and is usually susceptible to penicillin or cephalosporin. A better chance of eradicating the infection with antibiotics and drainage is possible with nonporous implants. In the presence of a purulent infection, the implant should be removed and scrubbed and sterilized to remove the biofilm. In addition, debridement and copious irrigation of the implant pocket and a prolonged postoperative antibiotic course are necessary. If rapid improvement does not occur and the implant needs to be removed, it should not be replaced for 6-8 weeks to allow for resolution of the infection and inflammation [50].

\subsection{Migration and contour changes}

Migration is usually the result of over dissection, improper implant size selection and lack of fixation. Supraperiosteal placement can predispose the implant to mobility especially without adequate fixation. Anatomic implants have decreased the potential for migration, rotation, and displacement. Delayed contour changes have been reported in association with silastic implants. This is thought to be associated with capsular contracture around the implant in addition to calcification of the capsule itself.

\subsection{Extrusion}

Adequate soft tissue bulk with good quality tissue for coverage of the implant and tensionfree correct plane insertion are critical to preventing implant extrusion. Decreased tissue perfusion causes wound healing problems. Highly scarred and thinned tissues tend to atrophy over time and are at a higher risk for postoperative infection, exposure, and extrusion [35]. Excessive tension is a result of placing too large an implant in a small pocket. In addition to tension free closure, subperiosteal placement helps prevent exposure.

\subsection{Palpability}

This can be the result of improper implant size selection, improper contour selection, improper positioning, improper fixation or capsular contracture. Thin overlying tissue and supraperiosteal placement of the implant predispose to palpability. 


\subsection{Lip dysfunction}

Altered lip function occurs because dissection can interfere with the muscles responsible for smiling mimetics. Other factors include edema, interposition of a solid implant which stretches the muscles of the midface, or interference with the facial nerve during dissection over the zygomatic arch. The edema can cause dysfunction in the muscles of the lips resembling facial nerve dysfunction. When dysfunction is due to muscle displacement, it usually takes 1-3 months for the muscles to reattach and the capsule to become soft and distensible.

\subsection{Bone resorption}

Bone erosion under alloplastic implants was a significant problem with early implants. It was often attributed to foreign body reaction between the implant and the bone or to pressure from the mentalis muscle against the implant. Improper implant positioning, pressure due to an oversized implant, subperiosteal placement and hardness of the implant were also considered.

The resorption from anatomic malar and chin implants is minimal and self-limiting. Bone erosion occurs less with anatomic extended implants because of greater distribution of the pressure forces over a broader anatomic area. Resorption appears to occur in the first 12 months after placement but can appear radiographically as soon as 2 months. Labial incompetence and hyperactive mentalis lead to pressure and migration of the implant superiorly onto the thinner bone of the alveolus, which predisposes to resorption. When severe resorption is present, the implant must be removed.

\subsection{Postoperative asymmetry}

Asymmetry is more likely to be noticed in malar implants. It is usually caused by initial malposition or by creation of asymmetric bilaterally dissected spaces. It can also be the result of unrecognized preoperative skeletal or soft tissue deficiencies. It is important to point out preexisting asymmetry before treatment selection. Although major asymmetries require a second surgery, minor asymmetries have a natural tendency to adjust and correct themselves over a 6-month postoperative period as healing progresses and the tissue around the implant relaxes and softens.

\section{Summary}

Loss of volume and volume shift occur in all regions of the face and neck and contribute to the aged appearance. Volume replacement and contour augmentation of the face are the essentials of facial cosmetic surgery. The development of less invasive volume replacement procedures has been an evolution in achieving better aesthetic results. These procedures include lifting procedures, injectable fillers, autologous fat transfer, and facial implants.

Facial volume augmentation by using facial implants is a very safe procedure that is used widely for facial rejuvenation which can be used concomitantly with other rejuvenation 
procedures. It is crucial for the cosmetic surgeons to be familiar with various implant materials and their advantages and disadvantages.

\section{Author details}

Farzin Sarkarat", Behnam Bohluli and Roozbeh Kahali

*Address all correspondence to: sarkarat@hotmail.com

Department of Oral and Maxillofacial Surgery, Bouali Hospital, Islamic Azad University of Medical Sciences, Tehran, Iran

\section{References}

[1] Sclafani AP, Romo T. Biology and chemistry of facial implants. Facial Plast Surg 2000;16(1):3-6.

[2] Eppley B. Alloplastic implantation. Plast Reconstr Surg 1999;104(6):1761-85.

[3] Terino EO. The art of alloplastic facial contouring. St. Louis (MO): Mosby; 2000.

[4] Terino EO. Facial contouring with alloplastic implants: aesthetic surgery that creates three dimensions. Facial Plast Surg 1999;7:55-83.

[5] Constantinides MS, Doud-Galli SK, Miller PJ, et al. Malar, submalar, midfacial implants. Facial Plast Surg 2000;16:35-44.

[6] Terino EO. Alloplastic facial contouring by zonal principles of skeletal anatomy. Clin Plast Surg 1992;19:487.

[7] Niamtu J: The adjustable vector deep plane midface lift. Atlas Oral Maxillofac Surg Clin North Am 12:199, 2004

[8] Watson S, Niamtu J, Cunningham L: Endoscopic midface lift, in Atlas of Oral and Maxillofacial Surgery Clinics of North America. Philadelphia, PA, WB Saunders, 2003, pp 145-155

[9] Niamtu J: The use of Restylane in cosmetic facial surgery. J Oral Maxillofac Surg $64: 317,2006$

[10] Niamtu J: Minimally invasive cosmetic surgery, in Oral and Maxillofacial Surgery Clinics of North America. Vol 17. Philadelphia, PA, Saunders, 2005, pp 17-27

[11] Steinsapir KD, Steinsapir SM: Deep-fill hyaluronic acid for the temporary treatment of the Naso-jugal groove: A report of 303 consecutive treatments. Ophthal Plast Reconstr Surg 22:344, 2006 
[12] Little JW: Applications of the classic dermal fat graft in primary and secondary facial rejuvenation. Plast Reconstr Surg 109:788, 2002

[13] Obagi S: Autologous fat augmentation for addressing facial volume loss. Oral Maxillofac Surg Clin North Am 17:99, 2005

[14] Roy D, Mangat DS: Facial implants. Dermatol Clin 23:541, 2005

[15] Binder WJ, Azizzadeh B, Binder WJ: Malar and submalar augmentation. Facial Plast Surg Clin North Am 16:11, 2008

[16] Quatela VC, Sabini P. Synthetic implants. In: Papel ID, editor. Facial plastic and reconstructive surgery. New York7 Thieme Medical Publishing; 2002. p. 61- 72.

[17] Silver WE. Malar augmentation. Facial Plast Surg 1992; 8:133- 9.

[18] Romo III T, Baskin JZ, Sclafani AP. Augmentation of the cheeks, chin and pre-jowl sulcus, and nasolabial folds. Facial Plast Surg 2001;17:67-78.

[19] Zide BM, Pfeifer TM, Longaker MT. Chin surgery: I. Augmentation - the allures and the alerts. Plast Reconstr Surg 1999;104:1843.

[20] Tardy ME, Thomas JR, Brown RJ. Facial aesthetic surgery. St. Louis (MO): Mosby; 1995.

[21] Auger TA, Turley PK. The female soft tissue profile as presented in fashion magazines during the 1900's. A photographic analysis. Intern J Adult Orthodon Orthognath Surg 1999;14:7-18.

[22] Perrett DI, May KA, Yoshodawa S. Facial shape and judgements of female attractiveness. Nature 1994; 368:239-42.

[23] Morehead JM, Holt GR. Soft-tissue response to synthetic biomaterials. Otolaryngol Clin North Am 1994;27(1):195-201.

[24] Albrektsson T, Branemark PI, Jacobsson M, et al. Present clinical applications of osseointegrated percutaneous implants. Plast Reconstr Surg 1987;79(5):721-31.

[25] Branemark PI, Albrektsson T. Titanium implants permanently penetrating human skin. Scand J Plast Reconstr Surg 1982;16(1):17-21.

[26] Wilson J, Merwin GE. Biomaterials for facial bone augmentation: comparative studies. J Biomed Mater Res 1988;22(A2 Suppl):159-77.

[27] Davis PK, Jones SM. The complications of silastic implants. Experience with 137 consecutive cases. Br J Plast Surg 1971;24(4):405-11.

[28] Silver FH, Maas CS. Biology of synthetic facial implant materials. Facial Plast Surg Clin North Am 1994;2:241-53. 
[29] Morrison AD, Sanderson RC, Moos KF. The use of Silastic as an orbital implant for reconstruction of orbital wall defects: review of 311 cases treated over 20 years. J Oral Maxillofac Surg 1995;53(4):412-7.

[30] Gross EJ, Hamilton MM, Ackermann K, et al. Mersilene mesh chin augmentation. A 14-year experience. Arch Facial Plast Surg 1999;1(3): 183-9 [discussion: 190].

[31] McCollough EG, Hom DB, Weigel MT, et al. Augmentation mentoplasty using Mersilene mesh. Arch Otolaryngol Head Neck Surg 1990; 116(10):1154-8.

[32] Choe KS, Stucki-McCormick SU. Chin augmentation. Facial Plast Surg 2000;16(1):4554 .

[33] Costantino PD, Friedman CD, Lane A. Synthetic biomaterials in facial plastic and reconstructive surgery. Facial Plast Surg 1993;9(1):1-15.

[34] Spector M, Flemming WR, Sauer BW. Early tissue infiltrate in porous polyethylene implants into bone: a scanning electron microscope study. J Biomed Mater Res 1975;9(5):537-42.

[35] Wellisz T, Kanel G, Anooshian RV. Characteristics of the tissue response to MEDPOR porous polyethylene implants in the human facial skeleton. J Long Term Eff Med Implants 1993;3(3):223-35.

[36] Gladstone HB, McDermott MW, Cooke DD. Implants for cranioplasty. Otolaryngol Clin North Am 1995;28(2):381-400.

[37] van Gool AV. Preformed polymethylmethacrylate cranioplasties: report of 45 cases. J Maxillofac Surg 1985;13(1):2-8.

[38] Abrahams IW. Repair of orbital floor defects with premolded plastic implant. Arch Ophthalmol 1966;75(4):510-2 \%R 10.1001/archopht.75.4.510.

[39] Maas CS, Gnepp DR, Bumpous J. Expanded polytetrafluoroethylene (Gore-Tex softtissue patch) in facial augmentation. Arch Otolaryngol Head Neck Surg 1993;119(9): 1008-14.

[40] Levine B, Berman WE. The current status of expanded polytetrafluoroethylene (Gore-Tex) in facial plastic surgery. Ear Nose Throat J 1995; 74(10):681-2, 684.

[41] Mole B. The use of Gore-Tex implants in aesthetic surgery of the face. Plast Reconstr Surg 1992;90(2):200-6.

[42] Scales J, Winter G. Clinical considerations in the choice of materials for orthopedic internal devices. J Biomed Mater Res 1975;9:167-76.

[43] Terino EO. Alloplastic facial contouring: surgery of the fourth plane. Aesthetic Plast Surg 1992;16:195- 212. 
[44] Bapna MS, Lautenschlager EP, Moser JB. The influences of electrical potential and surface finish on the fatigue life of surgical implant materials. J Biomed Mater Res 1975;9(6):611-21.

[45] Donald PJ. Cartilage grafting in facial reconstruction with special consideration of irradiated grafts. Laryngoscope 1986;96(7):786-807.

[46] Terino EO. Chin and malar augmentation. In: Complications and problems in aesthetic plastic surgery. New York: NY; 1992. Ch 6.

[47] Yarmechuck MJ. Infraorbital rim augmentation. Plast Reconstr Surg 2001;107(6): 1585-92.

[48] Sclafani AP, Thomas JR, Cox AJ, et al. Clinical and histologic response of subcutaneous expanded polytetraflouroethylene and porous high density polyethylene implants to acute and early infection. Arch Otolaryngol Head Neck Surg 1997;123: 32836.

[49] Cohen SR, Kawamoto HK. Infection of proplast malar implants following dental injections. Plast Reconstr Surg 1992;89(6):1148-51.

[50] Louis PJ, Cuzalina LA. Alloplastic augmentation of the face. Atlas Oral Maxillofac Surg Clin North Am 2000; 8(2):127-91. 